\title{
Kinin Release after Gastric Surgery
}

\author{
A. CUSCHIERI, O. A. ONABANJO
}

British Medical fournal, 1971, 3, 565-566

\begin{abstract}
Summary
Kinin studies were performed in six patients with vasomotor dumping after gastric surgery and in six control patients who had had similar surgical procedures without subsequent dumping. Depletion of the precursor, kininogen, was found in all the patients with dumping and increased free plasma kinin activity in four after a 50-g carbohydrate meal which precipitated an attack. No significant changes were found in the control group after a high carbohydrate intake.
\end{abstract}

\section{Introduction}

Vasodilator plasma kinins are generated by the action of proteolytic kininogenase enzymes on plasma globulin substrates, known as kininogens. Zeitlin and Smith (1966) studied patients who had had a gastrectomy in whom dumping attacks were provoked by a hypertonic $(20 \%)$ glucose meal. They found a greatly increased level of free plasma kinins during a dumping attack whereas the blood 5-hydroxytryptamine concentration remained within the normal range. Similar findings were reported by Blumel et al. (1967).

The present work was undertaken to -study plasma kinin generation after gastric surgery in (1) patients with vasomotor dumping and (2) patients without, who had previously had similar gastric surgery.

\section{Clinical Features and Methods}

Six patients (five men and one woman aged 29-43) with vasomotor dumping after gastric surgery were studied. Two had previously had Polya gastrectomy and four had had vagotomy and drainage. These patients were given a solid meal containing $50 \mathrm{~g}$ of carbohydrate. Peripheral venous blood samples were taken before the meal, at the height of the vasomotor symptoms, which occurred 20 to 40 minutes after the meal, and after the attack had subsided.

Six other patients, all men aged 25-39, acted as controls. Two had previously had partial gastrectomy and four had had vagotomy and drainage. All were in good health and had never experienced vasomotor dumping. They too received a solid meal containing $50 \mathrm{~g}$ of carbohydrate. Peripheral venous blood samples were taken before and 20 to 40 minutes after the meal.

All the patients were monitored for pulse rate, blood pressure, forearm skin temperature, and packed cell volume throughout the period of study. All the six dumping patients developed a vasomotor attack and two of them fainted momentarily. None of the six gastric controls developed any objective signs of vasomotor dumping though two complained of "tiredness" after the meal.

The venous blood samples $(6 \mathrm{ml})$ were collected in chilled

\section{University of Liverpool, Liverpool L69 3BX}

A. CUSCHIERI, M.D., CH.M., F.R.C.S.(ENG., ED.), Lecturer, Department of

O. A. ONABANJO, B.Sc., PH.D., School of Tropical Medicine (Present address: Department of Physiology, Faculty of Medicine, University of Ibadan, Nigeria) absolute ethanol and extracted for kininogen and free plasma kinin after the method of Brocklehurst and Zeitlin (1967). The bioassay was performed on the isolated rat uterus, previously stored at $4^{\circ} \mathrm{C}$ for a period of $12-18$ hours. The tissue was later suspended in a 5-ml bath of oxygenated de Jalon solution at 30 to $31^{\circ} \mathrm{C}$. A four-point assay technique against synthetic bradykinin (Sandoz, BRS 640) was performed in duplicate. The de Jalon solution contained atropine sulphate $\left(10^{-8} \mathrm{~g} / \mathrm{l}\right)$ and brom-lysergic acid diethylamide (BOL $10^{-8} \mathrm{~g} / 1$ ). All glassware was siliconized and the reagents used were of analar grade.

\section{Results}

During dumping there was a mean fall in the systolic pressure of $30 \mathrm{~mm} \mathrm{Hg}$, a mean rise in the pulse rate of 25 beats per minute, and a mean rise in the forearm skin temperature of $1 \cdot 1^{\circ} \mathrm{C}$. There was no significant change in the P.C.V. after a high carbohydrate meal in both dumping patients and gastric controls.

Venous Kininogen.-All six dumping patients showed a fall in the venous kininogen during an attack. This averaged 1.02 $\mu \mathrm{g} / \mathrm{ml}$, and was statistically significant $(P<0.02)$. When the attack subsided the venous kininogen rose to about the initial value (Table I). In the gastric controls the fasting venous kininogen was similar to that in the dumping group $(P>0.5)$ and showed no significant change after a high carbohydrate meal (Table II).

TABLE I-Venous Kininogen in Bradykinin Equivalents in 6 Dumping Patients (Mean and S.E.)

\begin{tabular}{l|c|c|c}
\hline & Before Meal & During Dumping & After Dumping \\
\hline Venous kininogen in $\mu \mathrm{g} / \mathrm{ml}$ & $4.38 \pm 0.6$ & $3.36 \pm 0.7$ & $4.47 \pm 0.5$ \\
\hline
\end{tabular}

TABLE II-Venous Kininogen in Bradykinin Equivalents 6 Gastric Controls (Mean and S.E.)

\begin{tabular}{lll|c|c}
\hline & & Before Meal & After Meal \\
\hline Venous kininogen in $\mu \mathrm{g} / \mathrm{ml}$ & $\ldots$ &.. & $3.8 \pm 0.3$ & $4.0 \pm 0.5$ \\
\hline
\end{tabular}

TABLE III-Free Kinin Levels during Dumping

\begin{tabular}{|c|c|c|c|c|c|c|}
\hline $\begin{array}{l}\text { Case No. } \\
\text { Bradykinin equivalents of free kinin } \\
\quad(\mathrm{ng} / \mathrm{ml}) \\
\begin{array}{lllll}. & \ldots & \ldots & \ldots\end{array}\end{array}$ & $\begin{array}{c}1 \\
40 \cdot 0\end{array}$ & 2 & $\begin{array}{c}3 \\
95 \cdot 0\end{array}$ & $\begin{array}{c}4 \\
110 \cdot 2\end{array}$ & $\begin{array}{c}5 \\
5 \cdot 0\end{array}$ & 32.5 \\
\hline
\end{tabular}

Free Plasma Kinins. - In four out of six patients who developed a dumping attack a raised plasma kinin activity was detected at the height of the vasomotor symptoms (Table III). This free kinin-like activity was inactivated by incubation with chymotrypsin $(250 \mu \mathrm{g} / \mathrm{ml})$ for one hour, indicating its polypeptide nature. Free plasma kinins were not detected in the gastric control group either before or after a high carbohydrate meal.

\section{Discussion}

There is now considerable evidence to show that 5-hydroxytryptamine is not immediately concerned with vasomotor 
dumping (Walker et al., 1962; Howe, 1964; Silver et al., 1965; Zeitlin and Smith, 1966).

In two patients raised free plasma kinins were not found during a dumping attack. This is probably due to loss of activity during collection of samples owing to the extremely short half-life of bradykinin in vivo ( 15 seconds). Our results support the findings of Zeitlin and Smith (1966) and provide further evidence for involvement of kinins during vasomotor dumping in man. The present work shows that there is no significant difference in the fasting venous kininogen after gastric surgery in patients with dumping symptoms and those without. Furthermore, postcibal kinin liberation does not occur in patients who had previously had gastric surgery but who do not experience vasomotor dumping attacks.

One possible mechanism for release of kinins during dumping is basec' on the findings of Amundsen and Nustad (1965), who showed the presence of kinin forming activity in cell homogenates of the alimentary tract of the rabbit. Subsequently, the relative concentrations of kallikrein at different levels of the gastrointestinal tract of the rat were determined by Zeitlin (1969), who found the intestinal kallikrein activity to be especially high in the duodenum and ileum.

This work was supported by a grant from the United Liverpool Hospitals. We would like to thank Professor R. Shields, Mr. Howell Hughes, and Dr. D. Annis for their interest and co-operation.

\section{References}

Amundsen, E., and Nustad, K. (1965). Fournal of Physiology, 179, 478. Blumel, G., Klauser, G., Neumayr, A., Peschl, L., and RettenbacherTeubner, H. (1967). Medizinische Welt, 46, 2751.

Brocklehurst, W. E., and Zeitlin, I. J. (1967). Fournal of Physiology, 191, 417.

Howe, C. T. (1964). Surgery, Gynecology and Obstetrics, 119, 92.

Silver, D., Anlyan, W. G., Postlethwait, R. W., Morgan, C. V., and Mengel, C. E. (1965). Annals of Surgery, 161, 995.

Walker, G. R., Turner, M. D., and Hardy, J. D. (1962). Surgical Forum,

13, 241. (1969). In Bradykinin and Related Kinins, ed. F. Sicuturi, M. A. Rocha e Silva, and Nathan Back, p. 329. New York, Plenum Press.

Zeitlin, I. J., and Smith, A. N. (1966). Lancet, 2, 986.

\title{
Intramuscular Lignocaine $2 \%$ and $10 \%$
}

\author{
PETER JEBSON
}

British Medical fournal, 1971, 3, 566-567

\section{Summary}

Studies in 10 male volunteers has shown that intramuscular injection of $10 \%$ lignocaine produces similar blood lignocaine levels to those obtained with larger volumes of a less concentrated preparation. Since no local or general complications occurred it is suggested that the $10 \%$ solution is suitable for clinical use.

\section{Introduction}

The use of lignocaine in the treatment of ventricular arrhythmias is now established. Attention has been drawn to the use of the intramuscular route for prophylaxis or treatment of patients suffering from these arrhythmias, especially in the domiciliary situation (Scott et al., 1968; Bellet el al., 1969). Intramuscular injection might avoid the problems associated with bolus or constant intravenous therapy, especially during transport to hospital. As the highest concentration of lignocaine at present available is $2 \%$, a large volume must be used. A small volume of high concentration injected intramuscularly would have advantages, but it is important to know that these solutions are not unduly toxic and do not cause local muscle damage. The purpose of this study was to compare absorption of $2 \%$ and $10 \%$ lignocaine in normal people in regard to blood levels and identify systemic effects during absorption. Local effects at the injection site were also compared.

\section{Methods}

Ten male volunteers under 35 years (mean weight $84 \pm 9 \mathrm{~kg}$ ) were given injections into the lateral aspect of the thigh on two

University of Edinburgh, Edinburgh EH3 9YW

PETER JEBSON, F.F.A. R.C.S., Lecturer/Clinical Tutor occasions separated by at least one week. On one occasion $2 \mathrm{ml}$ of $10 \%$ solution of lignocaine was used and on the other $10 \mathrm{ml}$ of $2 \%$ solution. The lignocaine injection was accompanied by the injection of the same volume of normal saline into the other thigh, the nature of the injections being unknown to the volunteer or experimenter until the code was later broken. Venous samples were taken at $5,10,15,30,45,60,90,120,180$, and 240 minutes after injection and lignocaine levels were estimated by gas chromatography (Keenaghan, 1968). The E.C.G. was monitored by standard lead II, heart rate was obtained by apical pulse, and blood pressure by sphygmomanometer. Respiratory rate was taken by direct counting. The injection site was examined immediately after injection, at 30 minutes, 4 and 24 hours, and 3 days after injection.

\section{Results}

Table I shows mean lignocaine levels in peripheral venous blood as varying with time. Analysis of variance showed no statistical significance between $2 \%$ and $10 \%$ for subject or time. A significant fall in heart rate from control $(P<0.01)$ occurred with both concentrations over the four-hour experiment. No other changes in cardiac rhythm were observed and no variations in blood pressure or respiration were found. Subjective signs of general toxicity did not occur in any case. Complaints at the time of injection (Table II) disappeared within five minutes of injection and, with the exception of one volunteer who after receiving $2 \%$ lignocaine still had bilateral tenderness at the injection site after three days, no local complications were seen. The subjects identified correctly the site of lignocaine injection on only 5 of the 20 occasions.

\section{Discussion}

If the range $1-1.5 \mu \mathrm{g} / \mathrm{ml}$ is assumed to be the minimum therapeutic level of lignocaine (Killip, 1968; Harrison and Alderman, 1970), this was not achieved when the mean levels of the two 